\title{
Interferon lambda inhibits dengue virus replication in epithelial cells
}

\author{
Helen K. Palma-Ocampo 1,3, Juan C. Flores-Alonso ${ }^{1}$, Verónica Vallejo-Ruiz ${ }^{1}$, Julio Reyes-Leyva', \\ Lilian Flores-Mendoza², Irma Herrera-Camacho ${ }^{4}$, Nora H. Rosas-Murrieta ${ }^{4}$ and Gerardo Santos-López ${ }^{1 *}$
}

\begin{abstract}
Background: In viral disease, infection is controlled at the cellular level by type I interferon (IFN-I), but dengue virus (DENV) has the ability to inhibit this response. Type III interferon, also known as lambda IFN (IFN-III or IFN- $\lambda$ ), is a complementary pathway to the antiviral response by IFN-I. This work analyzed the IFN- $\lambda$ (IFN-III) mediated antiviral response against DENV serotype 2 (DENV-2) infection.
\end{abstract}

Methods: Dengue fever patients were sampled to determine their IFN- $\lambda$ levels by ELISA. To study the IFN- $\lambda$ response during DENV infection we selected the epithelial cell line C33-A, and we demonstrated that it is permissive to DENV-2 infection. The effect of IFN- $\lambda$ on virus replication was determined in these cells, in parallel to the expression of IFN-stimulated genes (ISGS), and Suppressor of Cytokine Signaling (SOCS), genes measured by RT-qPCR.

Results: We found increased ( 1.8 times) serological IFN- $\lambda$ in dengue fever patients compared to healthy blood donors. IFN- $\lambda$ inhibited DENV-2 replication in a dose-dependent manner in vitro. The reduction of viral titer corresponded with increased ISG mRNA levels (MX1 and OAS1), with the highest inhibition occurring at ISG's peak expression. Presence of IFN-negative regulators, SOCS1 and SOCS3, during DENV-2 infection was associated with reduced IFN- $\lambda 1$ expression.

Conclusions: Evidence described here suggests that IFN- $\lambda$ is a good candidate inhibitor of viral replication in dengue infection. Mechanisms for the cellular and organismal interplay between DENV and IFN- $\lambda$ need to be further studied as they could provide insights into strategies to treat this disease. Furthermore, we report a novel epithelial model to study dengue infection in vitro.

Keywords: Dengue, DENV, DENV-2, Interferon $\lambda$, SOCS, IL-28A, IL-28B, IL-29, IFN-III, IFN- $\lambda$

\section{Background}

Dengue is an important public health problem: Using updated mapping approaches, there are 390 million estimated dengue infections per year worldwide, of which 96 million manifest clinically at some level of severity [1]. This leads to half a million hospitalizations and 25,000 deaths, mainly in children [2]. The etiological agent of dengue disease is the dengue virus (DENV), which is responsible for dengue fever (DF), dengue hemorrhagic fever (DHF) and dengue shock syndrome (DSS).

Dengue virus, a member of the Flaviviridae family, is an enveloped virus containing a $\sim 11 \mathrm{~kb}$ genome of

\footnotetext{
* Correspondence: gerardo.santos.lopez@gmail.com

'Laboratorio de Biología Molecular y Virología, Centro de Investigación Biomédica de Oriente, Instituto Mexicano del Seguro Social, Metepec, Puebla, México

Full list of author information is available at the end of the article
}

positive single-stranded RNA which encodes three structural proteins $(\mathrm{C}, \mathrm{pr}-\mathrm{M}, \mathrm{E})$ and seven nonstructural proteins (NS1, NS2A, NS2B, NS3, NS4A, NS4B, NS5) [3]. Four serotypes of dengue virus (DENV-1, DENV-2, DENV-3, and DENV-4) cause DF and more severe manifestations like DHF and DSS [4].

Dengue virus is transmitted by female mosquitoes mainly of the species Aedes aegypti and A. albopictus. The disease is widespread throughout the tropics, with local spatial risk variations influenced strongly by rainfall, temperature and unplanned rapid urbanization [5].

In many viral diseases, infection is controlled at the cellular level by type I interferon (IFN- $\alpha / \beta)$ produced in response of viral RNA. Recognition of IFN-I by its specific cell receptors activates the JAK-STAT signaling 
pathway, which leads to the establishment of an antiviral state in the cell. However, viruses possess diverse strategies to circumvent IFN effects [6].

DENV, like other viruses, has the ability to inhibit this innate response, which may contribute to its pathogenesis. DENV virus induces the activation and release of high levels of chemokines and pro-inflammatory cytokines in human dendritic cells, although it is a weak inducer of IFN-I, as it blocks IRF-3 phosphorylation, impairing subsequent IFN- $\alpha / \beta$ production [7].

There are three types of IFN. Type I comprises several subtypes of IFN- $\alpha$ and several other isoforms such as IFN $-\beta,-\varepsilon,-\kappa,-\delta,-\omega,-\tau$ and $-\zeta[8,9]$. Type II contains only one member, IFN- $\gamma$. The latest identified group, type III, comprises IFN- $\lambda 1$, IFN- $\lambda 2$, IFN- $\lambda 3$ (also named interleukin [IL]-29, IL-28A and IL-28B, respectively) and IFN- $\lambda 4$ [10-12], but there is limited information about their expression and biological functions. Furthermore, the role of IFN-III during DENV infection is unexplored.

IFN- $\lambda$ specific signaling occurs through its receptor on the cell membrane, which consists of two subunits: IL28R1 (also named IFN- $\lambda$ R1, IL28R $\alpha$ ) and IL-10 receptor 2 (IL-10R2) $[8,10,11]$. Most cells express the IL10R2 subunit, but IL28R1 distribution appears to be much more restricted. The receptor for IFN- $\lambda$ is expressed preferentially in cells of epithelial origin and in some cells of the immune system $[8,10,13]$.

Binding of IFN $-\lambda$ to its receptor leads to the activation of JAK1 and Tyk2, which mediate the phosphorylation of STAT1 and STAT2 proteins. STAT phosphorylation leads to their dimerization, binding to IRF9 and translocation into the nucleus where they regulate the expression of specific genes. IFN-III has similar functions to IFN-I, inducing an antiviral state in cells $[8,10,13]$ and mediates the antiviral response against several human pathogens including hepatitis $B$ virus, hepatitis $C$ virus and human immunodeficiency virus [13-15]. The restricted expression of its receptor suggests that the IFN- $\lambda$ could exert an antiviral role on certain cell types $[16,17]$.

There is no commercial vaccine or specific antiviral treatment for dengue; thus, the development of efficient therapeutic strategies against this common and sometimes severe infection is urgent. The antiviral activity of interferons has been observed in diverse clinical studies showing a relative efficiency against different viral infections. In 1984, Limonta Vidal et al. [18] introduced the use of leukocyte interferon to treat children with dengue, showing a significant decrease in the number of complications and deaths when interferon was applied. However, the clinical use of interferon to treat dengue is not common, possibly due to IFN- $\alpha$ side effects associated with its systemic activity. IFN- $\lambda$ is an attractive treatment alternative because it elicits a satisfactory antiviral activity with only a minor secondary response $[19,20]$.
Nevertheless, DENV has developed mechanisms to evade the immune response. Therefore, the precise analysis of IFN- $\lambda$ response during dengue infection is crucial to evaluate/predict its potential clinical uses in this disease.

The present work focuses on the effect in epithelial cells of IFN- $\lambda$ (IFN-III) on the DENV-2 infection. We found higher levels of IFN- $\lambda$ in dengue fever patients compared with healthy blood donors and we provide evidence that endogenous and exogenous IFN $-\lambda$ inhibit DENV-2 replication in the C33-A cell line.

\section{Results}

IFN- $\lambda$ levels in patients with dengue fever

To detect the presence of IFN- $\lambda$ during DENV infection, serum samples from patients with dengue fever were analyzed by ELISA. Levels of IFN- $\lambda(\lambda 1 / \lambda 3)$ were determined in serum samples from 10 patients with dengue fever and 10 healthy blood donors. Figure 1 shows the value distribution for each group; the mean was $106.9 \pm 9.05 \mathrm{pg} / \mathrm{ml}$ for DF patients and $58.71 \pm 6.86 \mathrm{pg} / \mathrm{ml}(p<0.001)$ for healthy donors.

\section{C33-A cells are permissive to DENV-2 infection}

To study the response of IFN- $\lambda$ during DENV-2 infection, we selected the epithelial cell line C33-A. Because DENV infection has not been reported infecting C33-A cells, we performed initial assays and analyzed whether these cells are permissive to infection. After DENV-2 replication in C33-A cells, viral titers in the supernatants at $48 \mathrm{~h}$ post-infection were quantified by lytic plaque assays in BHK-21 cells, meaning that infectious viral progeny was released from C33-A cells. Immunofluorescence analysis using a specific antibody against DENV pr-M protein (Fig. 2) confirmed that C33-A cells

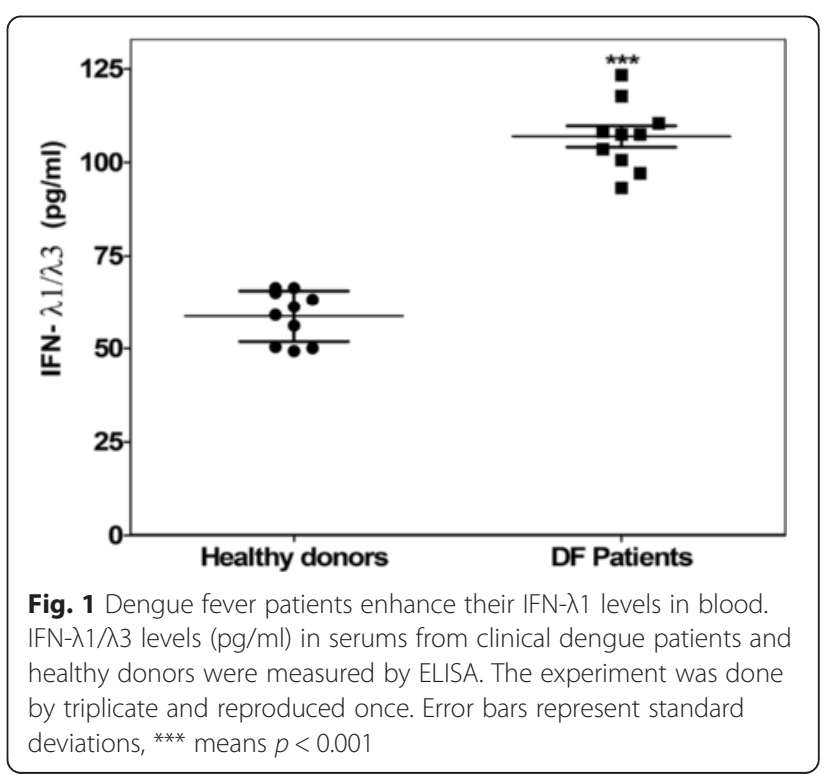



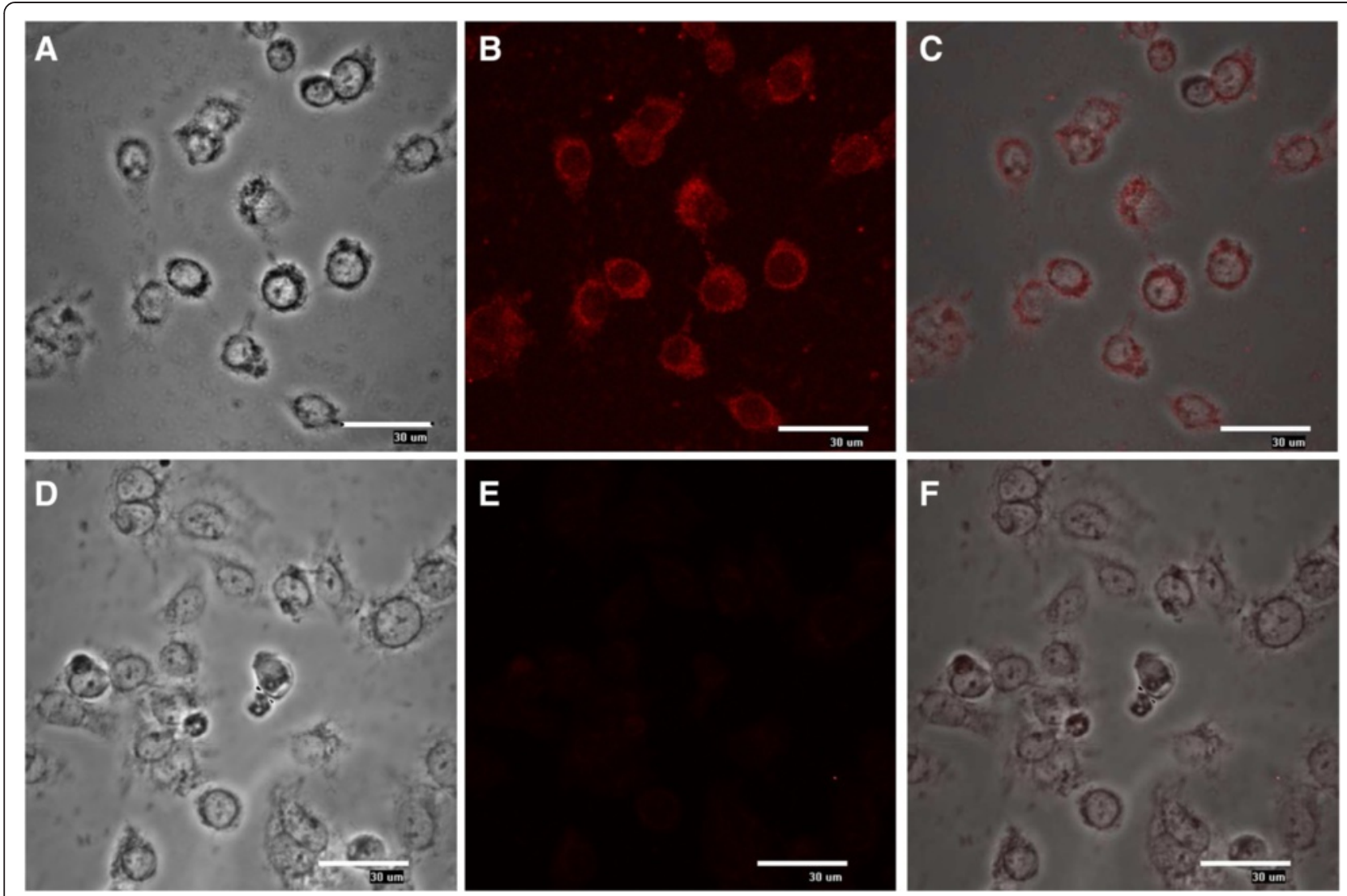

Fig. 2 Permissivity of C33-A cells to DENV-2 infection. Cells were infected with dengue virus (MOI=0.1) for 2 h, maintained for 24 h, washed, and fixed with methanol-acetone. The virus was detected using antibodies against the viral pr-M protein and a Texas Red secondary antibody and observed with fluorescence microscopy. a-c DENV-2-infected cells. d-f Mock-infected cells. a, d White light. b, e Fluorescence, (c, f) Merged images. Bars $=30 \mu \mathrm{m}$

are permissive to DENV-2 infection. Specific fluorescence was found in the cytoplasm of infected cells. With these data we propose the C33-A cell line as a novel epithelial model to analyze the relationship between DENV-2 infection and IFN- $\lambda$.

\section{DENV-2 infection and IFN- $\lambda 1$ increase the expression of IL28R1 in C33-A cells}

To analyze the effect of DENV-2 infection on signal transduction initiated by IFN-III, the tissue-specific IL28R1 subunit of type-III interferon receptor was quantified on C33-A cells, by immunofluorescence. Figure 3b shows the presence of IL28R1 at significant levels on the cell membrane of non-infected cells (red signal). Expression of this subunit increased $76 \%$ in the presence of IFN- $\lambda 1$ (Fig. 3f) and $61 \%$ during DENV-2 infection (Fig. 3d) with respect to untreated cells (quantification shown in Fig. $3 g$ ). Thus, DENV-2 and IFN- $\lambda 1$ upregulate to a similar extent the expression of the IL28R1 subunit of the IFN-III receptor, suggesting that differential effects between these two stimuli may lie at other points in the IFN- $\lambda$ signal transduction pathway.
DENV-2 replication induces the expression of IFN- $\lambda$ genes To determine whether DENV-2 induces the expression of all subtypes of IFN- $\lambda \mathrm{s}$, four treatments were compared: Mock infection, IFN- $\lambda 1$ treatment only (35 ng/ $\mathrm{ml})$, DENV-infection only $(\mathrm{MOI}=0.1)$, and IFN- $\lambda 1$ treatment followed by DENV infection. Mock-infected cells had no RT-PCR product for any of the IFN- $\lambda$ isoforms (Fig. 4a). In contrast, IFN- $\lambda 1$, IFN- $\lambda 2$ and IFN- $\lambda 3$ transcripts were demonstrated by end-point RT-PCR under the other three conditions studied (Fig. 4a).

To corroborate this result, total protein extracts from each condition were used for Western blot with specific antibodies against two subtypes of IFN-III ( $\lambda 1$ and $\lambda 2$ ). Figure $4 \mathrm{~b}$ shows that IFN- $\lambda 1$ and IFN- $\lambda 2$ are strongly induced by DENV-2 infection.

\section{IFN- $\lambda 1$ and IFN- $\lambda 2$ inhibit DENV-2 replication in a dose-dependent manner}

To explore the effect of IFN- $\lambda 1$ and IFN- $\lambda 2$ on the DENV-2 infection, a replication inhibition curve was determined. C33-A cells were pretreated with increasing concentrations of IFN- $\lambda 1$, IFN- $\lambda 2(0,10,20,30$ and 

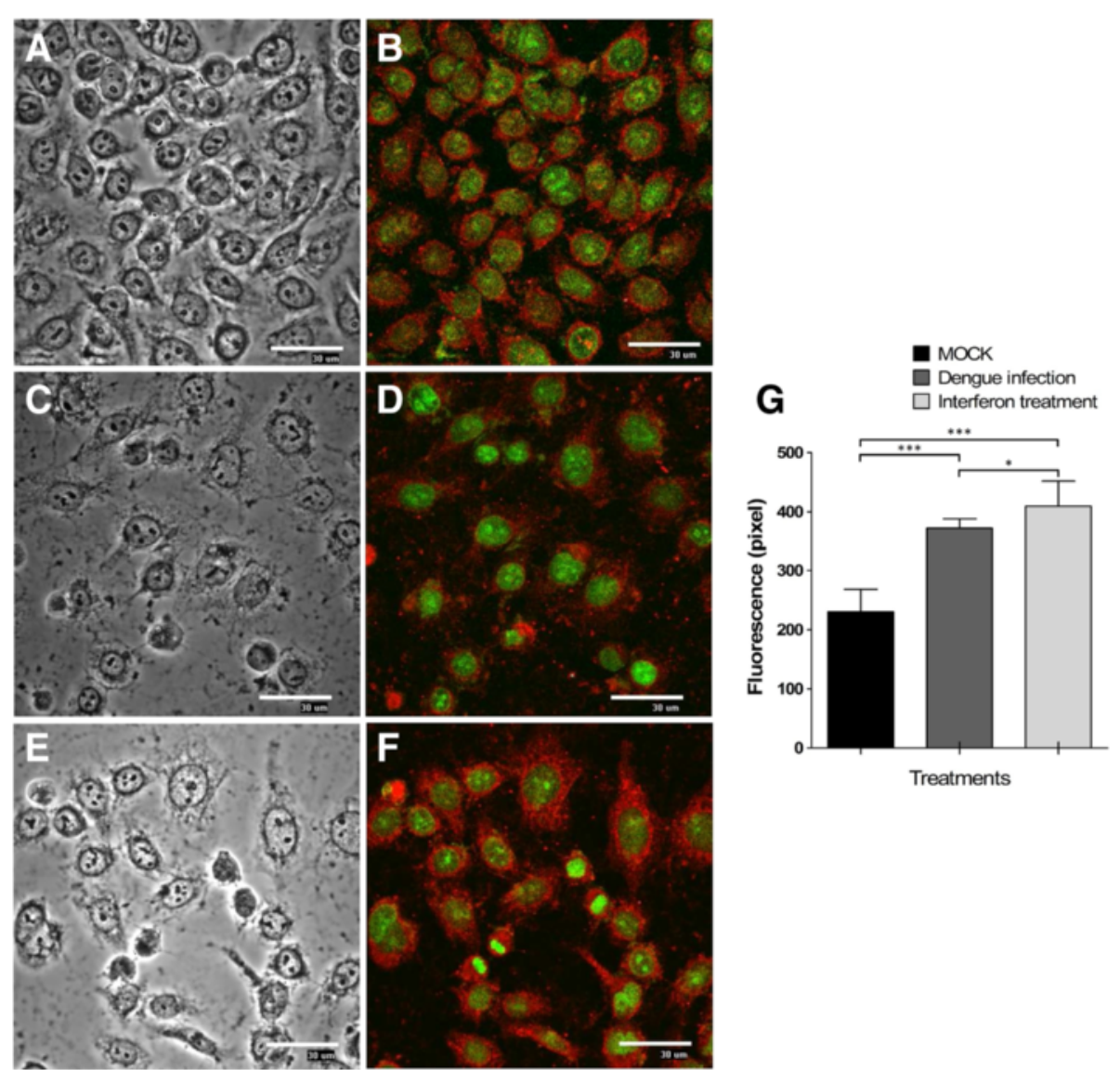

Fig. 3 Membrane receptor expression IL28R in C33-A cells. The presence of IL28R1 was determined in C33-A cells: (a, b) Mock-infected. (c, d) DENV-2 infected (MOI=0.1). e, f Treated with IFN- $\lambda 1$ (35 ng/ml). Immunofluorescence was detected with anti-IL28R1 and CFL647-Conjugated secondary antibody and observed by fluorescent microscopy (40X magnification). $\mathbf{g}$ Fluorescence intensities were determined by analysis of three different fields by randomly counting 50 cells using the image analysis software EZ-C1 v.2.3. ${ }^{*} p<0.05$, ${ }^{* *} p<0.001$. Nuclei were stained with the green fluorescent dye Sybr-14. Bars $=30 \mu \mathrm{m}$

$40 \mathrm{ng} / \mathrm{ml})$ or IFN- $\alpha(0,100,200,300$ and $400 \mathrm{IU} / \mathrm{ml})$ prior to infection with DENV-2 $(\mathrm{MOI}=0.1)$. Fortyeight hours after infection, the supernatants from each condition were quantified by lytic plaque-forming assays (Fig. 5).

Figure 5 shows that IFN- $\lambda 1$ and IFN- $\lambda 2$ inhibited DENV-2 replication in a dose-dependent manner, with relatively high inhibitory effect: IC50 $=8.705 \mathrm{ng} / \mathrm{ml}$, IC90 $=17.78 \mathrm{ng} / \mathrm{ml}$ for IFN- $\lambda 1$ (Fig. $5 \mathrm{~b}$ ) and $\mathrm{IC} 50=$ $8.24 \mathrm{ng} / \mathrm{ml}$, IC90 $=16.2 \mathrm{ng} / \mathrm{ml}$ ) for IFN- $\lambda 2$ (Fig. $5 \mathrm{c}$ ); whereas the IC50 for IFN- $\alpha$ was $122-138 \mathrm{IU} / \mathrm{ml}$ and IC90 $=380-398 \mathrm{IU} / \mathrm{ml}$ (Fig. 5a). These experiments showed that exogenous administration of IFN- $\lambda$ prior to infection reduces the viral titer of DENV-2.

Subsequently, viral replication in the C33-A cells was determined on lytic plaque-forming assays at different time post-infection $(0,6,12,18,24$ and $48 \mathrm{~h})$. Two infectious doses (MOI $=0.1$ and 1.0 ) were assayed. Cells pretreated with $10 \mathrm{ng} / \mathrm{ml}$ of IFN- $\lambda 1$ (Fig. 6a) or IFN- $\lambda 2$ (Fig. 6b) for $6 \mathrm{~h}$ prior to infection were compared to cells that were infected but not treated with IFN. The plots show an equivalent effect of IFN- $\lambda 1$ and IFN- $\lambda 2$ pre-treatment on viral titers, which were reduced by 1.5-2 logs with respect to mock-treated cells.

\section{IFN- $\lambda 1$ inhibits DENV-2 replication in cells lacking type I IFN}

To determine whether IFN- $\lambda 1$ is enough to inhibit replication of DENV-2, we tested its ability to inhibit viral replication in the absence of INF- $\alpha$. Inhibition experiments were similar to those described in Fig. 5, but they were performed on Vero cells that do not produce IFN- $\alpha$, yet respond to it if supplied externally [21]. Vero cells were pre-incubated for $6 \mathrm{~h}$ with increasing concentrations of IFN- $\alpha$, IFN- $\lambda 1$ or IFN- $\lambda 1$ plus IFN- $\alpha$ and then infected with DENV-2. By itself, IFN- $\lambda 1$ treatment decreased the viral progeny $50 \%$ at $37.15 \mathrm{ng} / \mathrm{ml}$ (IC50) (Fig. 7b). Treatment with IFN- $\lambda 1$ plus IFN- $\alpha$ had a lower IC50 of $14.12 \mathrm{ng} / \mathrm{ml}$ calculated for IFN- $\lambda 1$ (Fig. 7c); while for IFN- $\alpha$ treatment alone, IC50 couldn't be calculated 


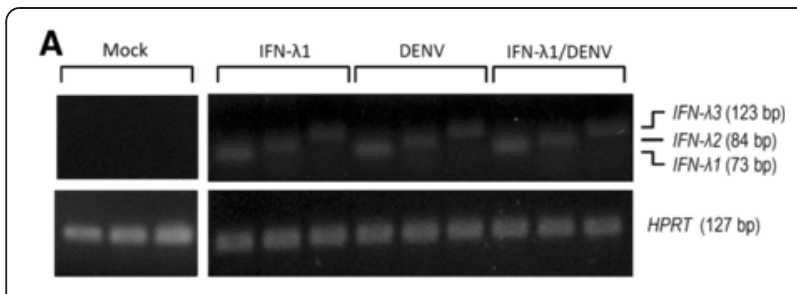

B

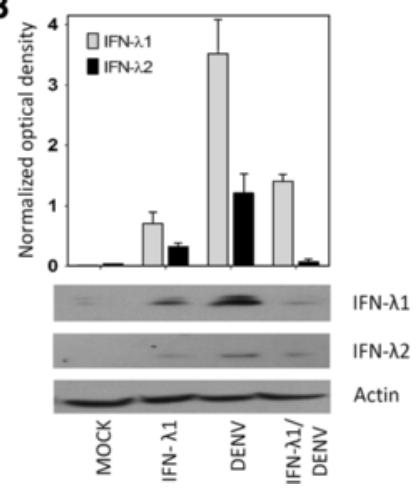

Fig. 4 DENV-2 induces the expression of IFN-III in C33-A cells. C33-A cells were treated with IFN- $\lambda 1(35 \mathrm{ng} / \mathrm{ml})$ infected with DENV-2 $(\mathrm{MOI}=0.1)$ or pre-treated with IFN- $\lambda 1$ and subsequently infected with DENV-2. Forty-eight h post-infection, total cellular RNA was isolated and used in end-point RT-PCR for qualitative determination of the IFN- $\lambda 1$, IFN- $\lambda 2$, IFN- $\lambda 3$ genes, using HPRT as an endogenous control gene. a Results of RT-PCR amplification of mock-infected and the three experimental conditions are shown. b Extracts of total protein from each condition were used for Western blotting to determine the presence of IFN- $\lambda 1$ and IFN- $\lambda 2$ proteins. Actin was the loading control. A semi quantitative analysis of detected bands normalized to actin was performed using ImageJ software (http://rsb.info.nih.gov/ij/)

because the $50 \%$ inhibition was not reached under the experimental conditions (Fig. 7a). This experiment suggests that IFN- $\lambda 1$ is able to inhibit DENV-2 infection, but an effective response likely involves both types of interferons and a possible synergism between them.

\section{Pre-treatment with IFN- $\lambda 1$ induces expression of ISGs that prevents viral replication}

Expression kinetics of IFN-stimulated genes (ISGs) was analyzed in C33-A cells by quantitative real-time PCR (RT-qPCR) for the same experimental groups described in Fig. 4 (Mock infection, IFN- $\lambda 1$ treatment, DENVinfection and IFN- $\lambda 1$ followed by DENV infection). For this analysis, we selected the OAS1 and MX1 genes as indicative of interferon pathway functionality for the antiviral response, the IFN- $\lambda 1$ and IFN- $\beta$ genes, and two negative regulatory genes, SOCS1 and SOCS3.

Figure 8a shows that stimulation of C33-A cells with IFN- $\lambda 1$ slightly increases the transcription of OAS1 to similar levels between 6 and $48 \mathrm{~h}$ post-treatment (pt). DENV-2 infection significantly increases OAS1 mRNA
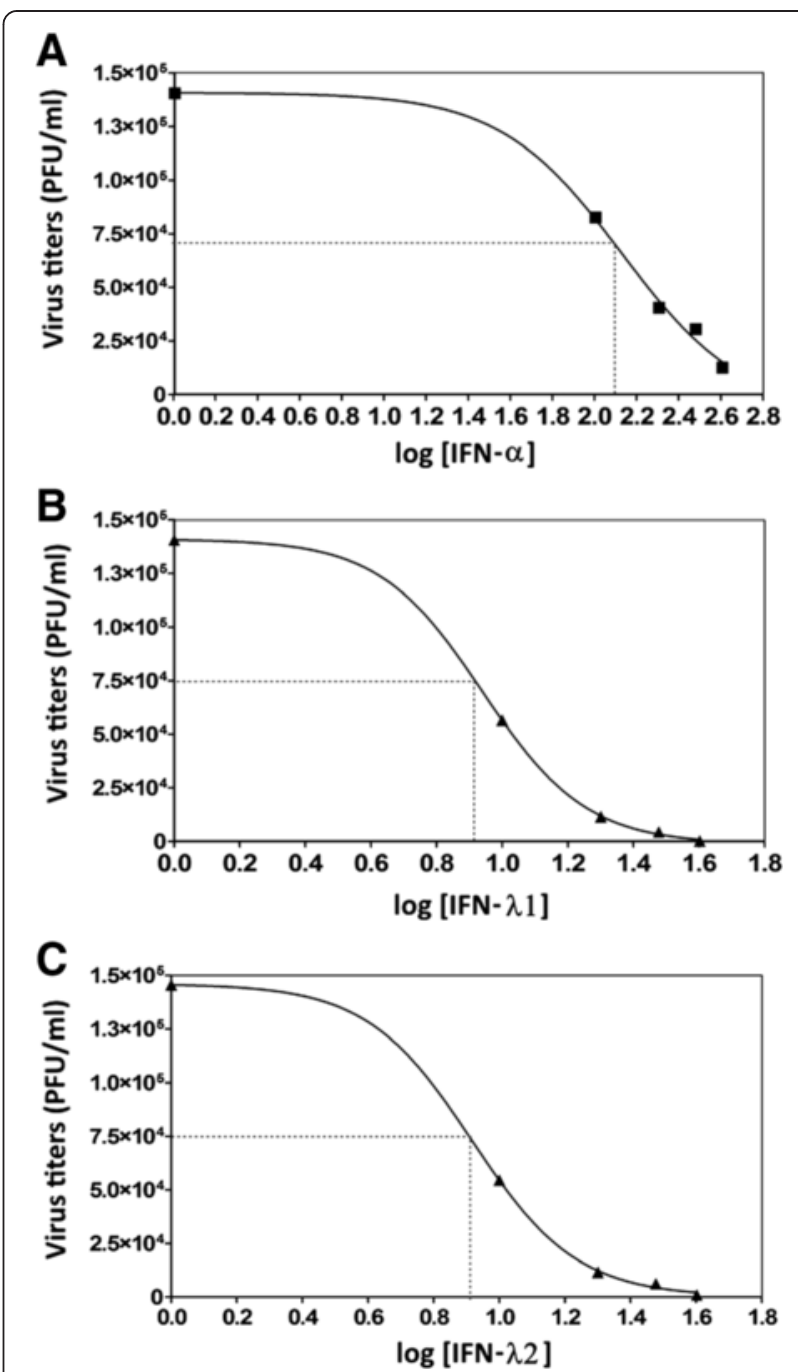

Fig. 5 IFN- $\lambda$ inhibits DENV-2 replication in a dose-dependent manner. C33-A cells were treated with increasing concentrations of IFN- $-a(\mathbf{a})$, IFN- $\lambda 1$ (b) or IFN- $\lambda 2$ (c) and then infected by DENV-2 $(\mathrm{MOI}=0.1)$. Forty-eight hours post-infection, the viral titer was obtained by plaque assay. The doses used were $10-40 \mathrm{ng} / \mathrm{mL}$ for IFN $\lambda 1$ or IFN- $\lambda 2$ and $100-400 \mathrm{UI} / \mathrm{ml}$ for IFN-a. Plots show the percentage inhibition of the viral titer in each group compared to untreated cells. Dotted lines represent the IC50 values corresponding to IFN- $\lambda 1=8.705 \mathrm{ng} / \mathrm{ml}$, IFN- $\lambda 2=8.24 \mathrm{ng} / \mathrm{ml}$, IFN- $\alpha=122-138 \mathrm{IU} / \mathrm{ml}$. The points are representative of two independent experiments performed in triplicate. Experiments were fit to the Hill equation, using nonlinear regression to estimate the IC50 of IFN- $\lambda 1$, IFN- $\lambda 2$ or IFN- (concentration of IFN that inhibited DENV-PFU production by $50 \%$, compared with parallel IFN free infected cultures). These IC50 values were considered for subsequent experimental procedures

but at earlier times, peaking at $6 \mathrm{~h}$ post-infection. However, the most striking effect was present with IFN- $\lambda 1$ pre-treatment followed by DENV-2 infection, that showed a pronounced increase in OAS1 expression from 6 to $18 \mathrm{~h}$ post-infection, at which time it peaked and then underwent a slow steady decrease, remaining 


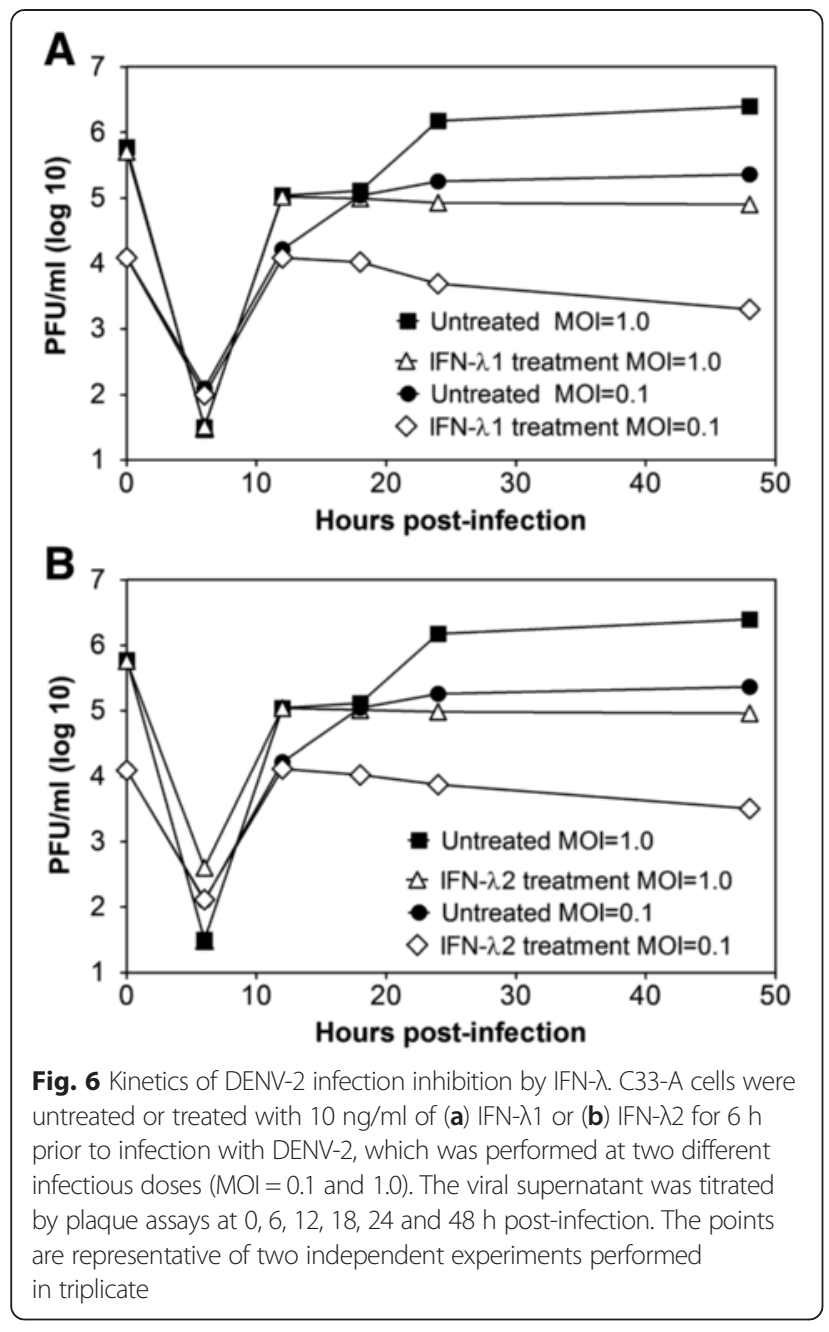

high at 24 and $48 \mathrm{~h}$. This result suggests that IFN- $\lambda 1$ decreases DENV-2 replication in part by viral mRNA degradation via RNase L. Moreover, stimulation of cells with IFN- $\lambda 1$ dramatically increases MX1 gene transcription, suggesting that the efficient activation of IFN-III signal transduction is useful in controlling DENV-2 infection. IFN- $\lambda 1$ treatment induced a bimodal MX1 increase with a first peak at $6 \mathrm{~h}$ post-infection and a second peak nearly 100 -fold higher than basal at $24 \mathrm{~h}$ (Fig. 8b). Bimodality probably is due as a result of a first wave of activation by IFN- $\beta$ and IFN- $\lambda 1$ and subsequently, the increase at $24 \mathrm{~h}$ could be by IFN- $\lambda 2$, which has demonstrated late induction, as well as by the late wave of endogenous interferons [22]. MX1 mRNA was detected at similar levels in infected and non-infected cells at all the studied times, suggesting that DENV induces an impairment in IFN signal transduction; however, this experiment cannot discriminate between IFN-I or IFN-III specific pathways. In cells pre-treated with IFN- $\lambda 1$ and then infected, MX1 mRNA increased between 18 and $48 \mathrm{~h}$ post-infection, although not as much as OAS1.

To determine if DENV-2 has differential effects on the activation of IFN-I and IFN-III, mRNA levels of IFN- $\beta$ (IFN-I) and IFN- $\lambda 1$ (IFN-III) were quantified. Figure $8 \mathrm{c}$ shows that IFN- $\beta$ mRNA is not increased at all in cells infected with DENV-2 at any of the studied times. IFN$\lambda 1$ stimulation increased IFN- $\beta$ mRNA $\sim 20-30$ times between 6 and $24 \mathrm{~h}$ post-treatment. In contrast, IFN- $\lambda 1$ pre-treatment followed by DENV-2 infection showed a $<10$-fold increase in IFN- $\beta$ mRNA, remaining much lower than with IFN- $\lambda 1$ stimulation alone. Therefore, it is believe that DENV-2 could affect the transcription of the IFN- $\beta$ gene, probably by affecting IRFs.

In contrast, the three experimental conditions induced intense, bimodal stimulation of IFN- $\lambda 1$ expression, with peaks at 6 and $48 \mathrm{~h}$ post treatment (Fig. $8 \mathrm{~d}$ ). IFN- $\lambda 1$ treatment alone, increased IFN- $\lambda 1$ mRNA 70 -fold at $6 \mathrm{~h}$ and 170 -fold at $48 \mathrm{~h}$ post-treatment; while DENV-2 and IFN- $\lambda 1$ treatment followed by infection increased IFN$\lambda 1$ levels somewhat less (65-fold and 55-fold for DENV-2 and 40-fold and 120-fold for IFN- $\lambda 1 /$ DENV-2, at $6 \mathrm{~h}$ and $48 \mathrm{~h}$ post-infection, respectively). The similar expression kinetics in Fig. $8 \mathrm{~b}$ and $\mathrm{c}$, in contrast to Fig. 8d, suggests that the inhibition of MX1 transcription in DENV-2 infection could be due primarily to lack of IFN-I.

Other important factors in the IFN pathway are the negative regulators SOCS1 and SOCS3, which increased from $12 \mathrm{~h}$ post infection (Fig. 8e and f). It is noteworthy that DENV-2 infection induces a significant SOCS1 increase that peaks at $24 \mathrm{~h}$ (40-fold), whereas in IFN- $\lambda 1$ stimulation and subsequent infection this increase was impaired and reached only 20 -fold at $24 \mathrm{~h}$.

\section{Increase in SOCS1 mRNA coincides with a decrease in IFN- $\lambda 1$ transcription}

In order to analyze other aspects of expression kinetics, the same data from Fig. 8 were re-plotted in Fig. 9 but grouped by experimental condition. Control cells (mockinfected) did not show significant activation of any gene tested, indicating that an external stimulus is required to activate their transcription in the evaluated conditions (Fig. 9a).

IFN- $\lambda 1$ mRNA peaked at $6-12 \mathrm{~h}$ and $48 \mathrm{~h}$ posttreatment (Fig. 9b). DENV-2 infection stimulated the transcription of IFN- $\lambda 1$, but the maximum value at $48 \mathrm{~h}$ post-treatment and was $65 \%$ lower than in IFN- $\lambda 1$ treated cells (open circles in Fig. 9b vs c).

For OAS1, the highest mRNA level was observed in cells treated with IFN- $\lambda 1 / \mathrm{DENV}-2$ at $18 \mathrm{~h}$ post-infection (Fig. 9d). DENV-2 infection increased the IFN- $\lambda 1$ transcription compared to non-infected cells treated with 

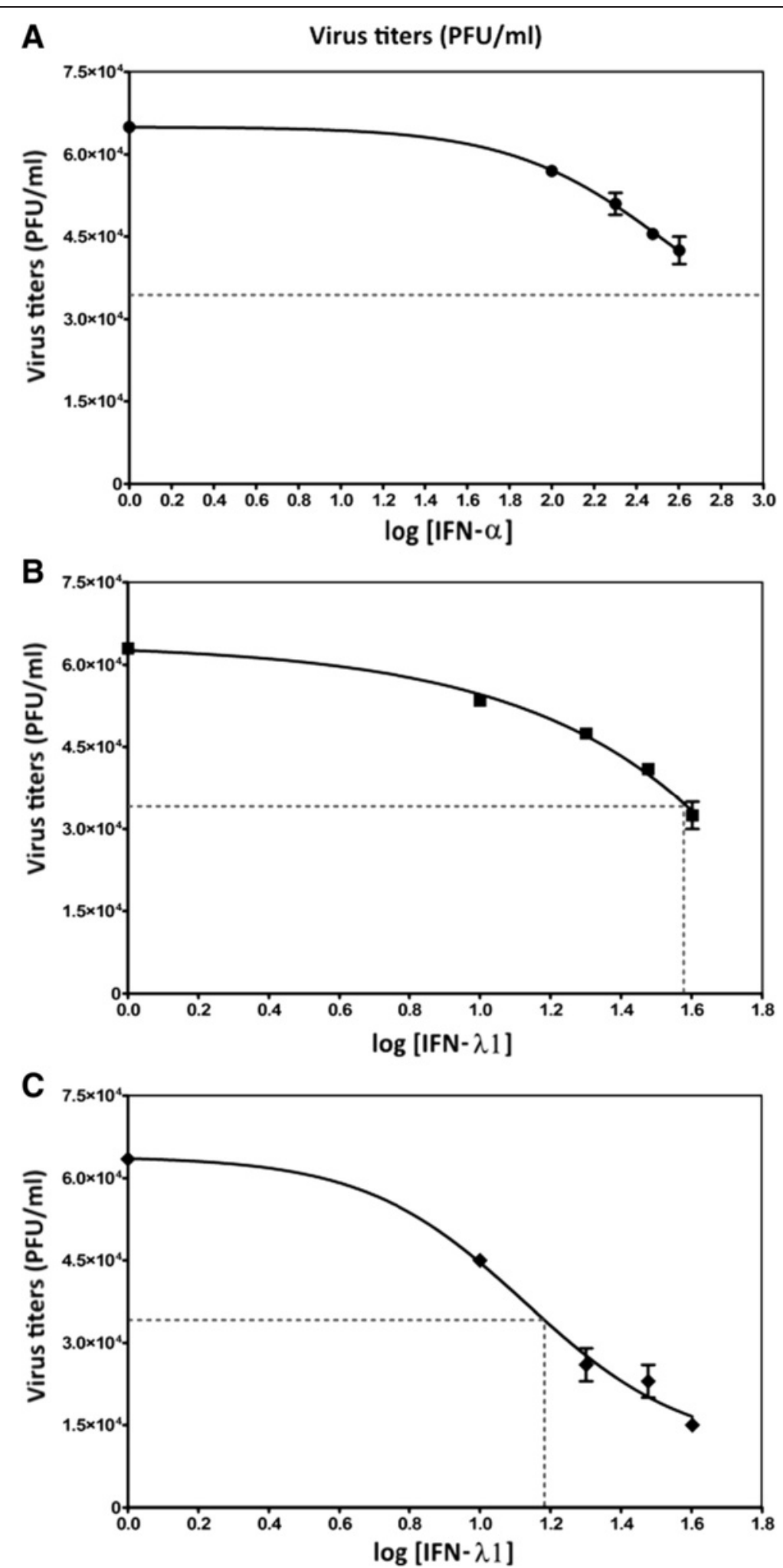

Fig. 7 (See legend on next page.) 
(See figure on previous page.)

Fig. 7 IFN- $\lambda 1$ inhibits DENV-2 replication in cells lacking type I IFN. Vero cells were treated with increasing concentrations of IFN-a (a) or IFN- $\lambda 1$ (b) or IFN- $\lambda 1$ plus IFN-a (c), and then infected by DENV-2 (MOI=0.1). The doses used were $10-40 \mathrm{ng} / \mathrm{ml}$ of IFN- $\lambda 1$ or $100-400 \mathrm{UI} / \mathrm{ml}$ of IFN-a. Forty-eight hours post-infection, the viral titer was obtained by plaque assay. Plots show the percentage inhibition of the viral titer in each group compared to untreated cells. Dotted lines represent the $I_{50}$ values corresponding to IFN- $\lambda 1=37.15 \mathrm{ng} / \mathrm{ml}$, IFN- $\lambda 1$ in presence of IFN- $\alpha=14.12 \mathrm{ng} / \mathrm{ml}$, the value of IC50 for IFN-a was not calculated because $50 \%$ inhibition was not reached under the conditions of experiment. Error bars represent standard deviations of means from two independent experiment ${ }^{*} p<0.01,{ }^{* *} p<0.001$

IFN- $\lambda 1$. Conversely, the highest level of MX1 transcript was observed in the IFN- $\lambda 1$-treated group at $6 \mathrm{~h}$ (40-fold) and $24 \mathrm{~h}$ (90-fold) (Fig. 9c). In addition, a steady increase in MX1 starting at $12 \mathrm{~h}$ post-infection and reaching 25 -fold, was observed in the IFN- $\lambda 1 /$ DENV- 2 group (Fig. 9d). This increase was smaller than in cells stimulated only by IFN- $\lambda 1$ (Fig. 9c) and it is of particular interest because the DENV-2-infected group did not show a significant increase in MX1 expression at any of the evaluated times.
The IFN negative regulators SOCS1 and SOCS3 showed maximum amounts at $6-12 \mathrm{~h}$ and $24 \mathrm{~h}$ post-stimulation with IFN- $\lambda 1$. DENV2 infection also elicited an increment in their expression which was much stronger for SOCS1. Their activation coincided with that observed after DENV-2 infection but was even stronger. The IFN- $\lambda 1 /$ DENV-2 experimental condition showed the highest expression of both genes at $12 \mathrm{~h}$ post-infection but it dropped to $40 \%$ of the DENV-2-only expression level by $48 \mathrm{~h}$ post-infection. It was also evident that the peak
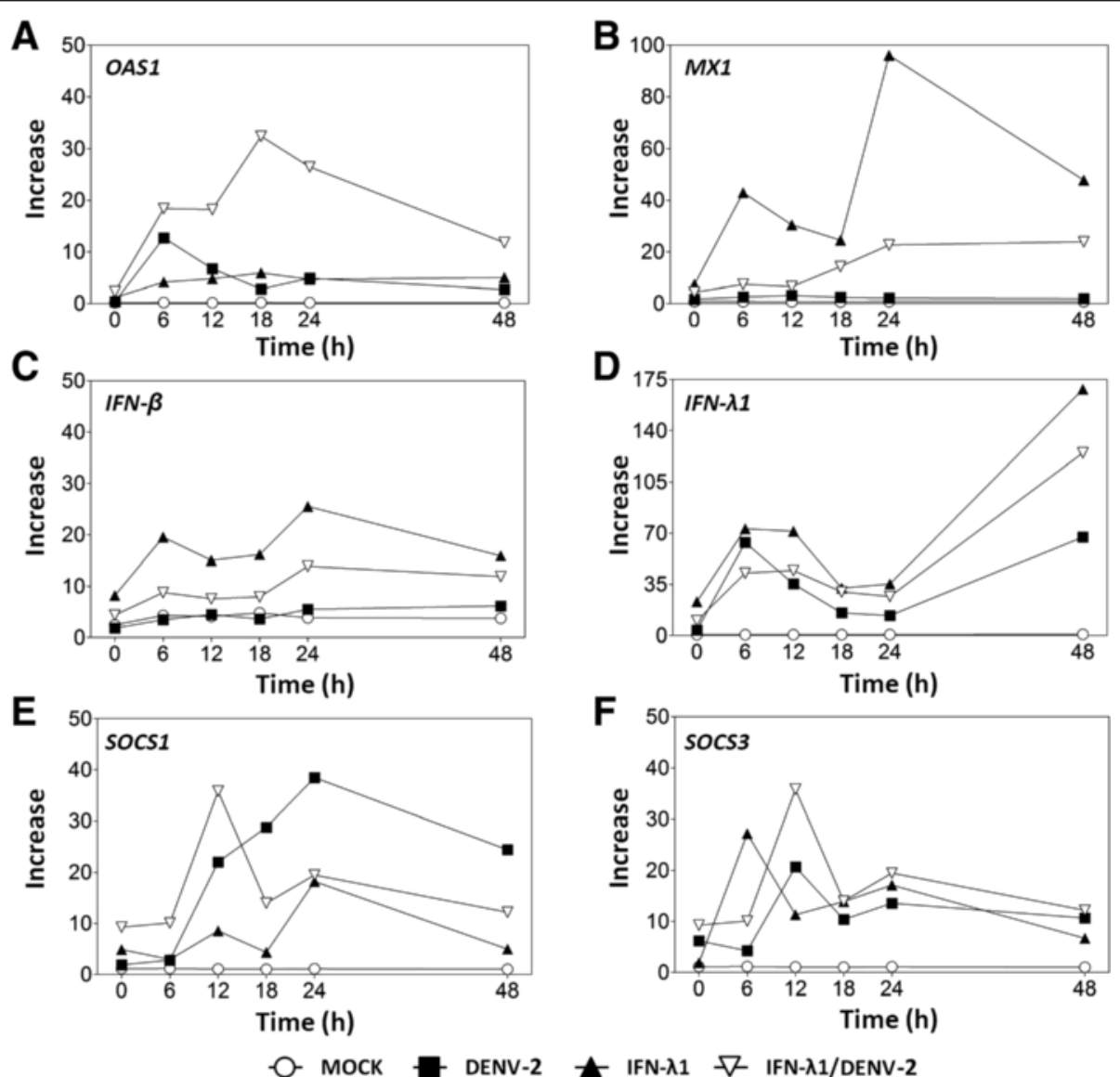

Fig. 8 Transcription levels of IFN-stimulated genes during DENV-2 infection. Expression of OAS1 (a), MX1 (b), IFN- $\beta$ (c), IFN- $\lambda 1$ (d), SOCS1 (e), and SOCS3 genes $(\mathbf{f})$ in cells infected with DENV-2 $(\mathrm{MOI}=0.1)$ or treated with $10 \mathrm{ng} / \mathrm{ml}$ of IFN- $\lambda 1$ or treated with IFN- $\lambda 1$ before DENV- 2 infection, were determined by RT-qPCR at $0,6,12,18,24$, and $48 \mathrm{~h}$ post-infection or post-treatment. Results are presented as expression relative to untreated cells, which have a value of 1. mRNA levels were normalized to the HPRT gene. Data points represent the mean of three replicates and error bars indicate standard deviation 

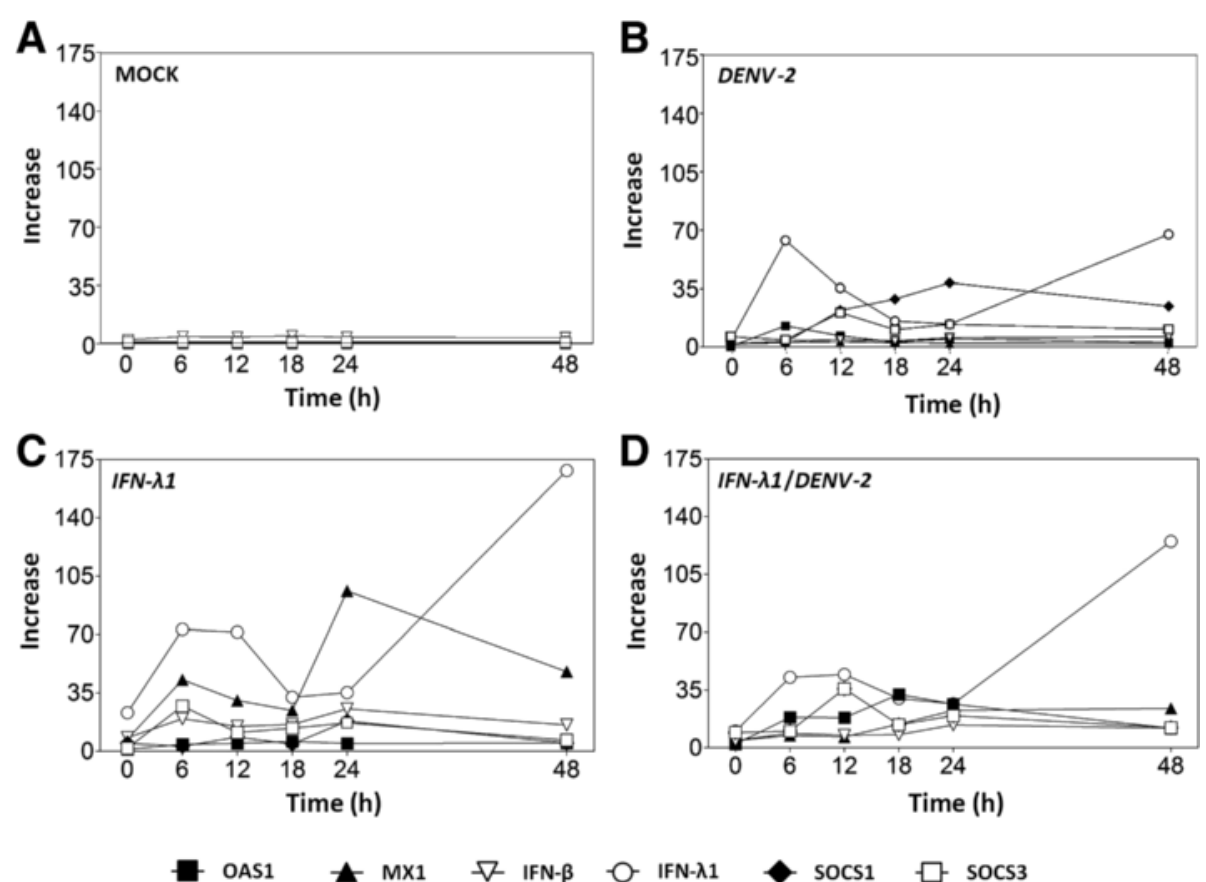

Fig. 9 Increase in SOCS1 coincides with a fall in IFN- $\lambda 1$ transcription. The same values used in the graphs of Fig. 8 were re-plotted and sorted according to experimental condition: (a) mock-infected cells, (b) infected with DENV-2 (MOI=0.1), (c) treated with $10 \mathrm{ng} / \mathrm{ml}$ of IFN- $\lambda 1$ or (d) treated with IFN- $\lambda 1$ prior DENV-2 infection. Data points represent the mean of three replicates and error bars indicate standard deviation

of SOCS1 expression during DENV-2 infection, coincided with a drop in IFN- $\lambda 1$ expression (Fig. 9b).

\section{Discussion}

IFN-III is the most recently identified interferon group [10-12], and there is limited information about its expression and biological functions. The particular role of IFN-III during DENV infection is unexplored. Although most cells respond to IFN-I, certain cell types, especially epithelial cells, can respond to IFN-III due to the restriction in receptor IL28R1 expression [23, 24].

In the present work we demonstrated that dengue fever patients had $\sim 1.8$ times higher IFN- $\lambda$ levels compared to healthy blood donors $(p<0.001)$. We are conducting further studies to answer whether IFN- $\lambda$ plays a role in viral clearance or in the generation of specific clinical outcomes. For IFN- $\alpha$, for instance, a recent study found higher levels in DF than DHF patients infected by DENV-1 or 2, that declined rapidly at day 3 after fever onset [25]. Such studies require the analysis of many patients, the determination of disease severity and the inclusion of patients infected with different DENV serotypes, among other variables.

Epithelial cells are IFN-III's main target. An analysis of IL28R1 receptor expression in mouse cells showed that vaginal epithelium and keratinocytes but not fibroblasts respond to IFN- $\lambda$ [23]. Several studies have been conducted in cell lines and primary cell cultures to study IFN- $\lambda$ response [26]. In the present study we found that the C33-A cervical, epithelial cell line is permissive to DENV-2 infection and that this cell line both produces and responds to IFN- $\lambda$. IL28R1, which is essential to support the antiviral action of IFN- $\lambda$, is expressed in C33-A cells. IL28R1 expression is inducible under viral infections, concurrent with the expression of IFN $-\lambda$ [16]. Accordingly, IL28R1 expression increased during DENV-2 infection in C33-A cells, which could potentiate the effect of IFN- $\lambda$ signalling, leading to stimulation of gene transcription for the antiviral response and to inhibition of DENV-2 replication; as has been demonstrated for HCV, HIV and HBV infections [15, 27].

The present study demonstrated the ability of IFN- $\lambda$ in the inhibition of DENV-2 replication. IFN- $\lambda$ reduced the amount of infectious particles secreted into the supernatant of C33-A cultures, quantified by plaque assays. Treatment with IFN- $\lambda$ or IFN- $\alpha$ decreased the viral titer. Dose-response experiments showed that the IC50 values for IFN- $\lambda 1$ and IFN- $\lambda 2$ were $8.24 \mathrm{ng} / \mathrm{ml}$ and $8.705 \mathrm{ng} / \mathrm{ml}$, respectively (Fig. 5). In view of these IC50 values, we tested whether an IFN- $\lambda$ concentration of $10 \mathrm{ng} / \mathrm{ml}$, which produces optimal gene induction in other viral infections $[28,29]$, could induce the expression 
of antiviral response genes during dengue infection. In a study involving West Nile virus (WNV), another member of the Flaviviridae family, induction of IFN- $\lambda$ and JAK/STAT pathway activation was demonstrated in infected cells. IFN- $\lambda$ was able to prevent WNV infection of naïve cells, but failed to inhibit viral replication in cells once infection had been established, likely due to IFN- $\lambda$ inhibition [30].

Furthermore, we report the IFN- $\lambda 1$-mediated inhibition of DENV-2 replication in Vero cells, which are devoid of IFN-I, but have functional IFN-III responses. These data suggest that dengue virus and the IFN- $\lambda$ treatment can active ISGs without type I IFNs. However, pre-treatment with IFN- $\lambda 1$ before dengue infection was not able to inhibit viral replication to the same degree in Vero as in C33-A cells, which shows that dengue virus can block activated signalling pathways that induce both type I and III interferons. Since viral titers did not decrease markedly with the highest IFN- $\lambda 1$ doses used, the data suggest that viral replication can be inhibited, albeit weakly, by endogenous and exogenous IFN- $\lambda 1$ in complete absence of IFN-I. Furthermore, the reduction in viral progeny observed with IFN- $\lambda 1+$ IFN- $\alpha$, suggests that both interferons work synergistically. Importantly, the MX1 gene can be induced in Vero cells stimulated with recombinant type I interferon, thus demonstrating that although these cells don't produce IFN-I they respond to it $[21,31,32]$.

The antiviral effect shown by IFN-III could occur through the stimulation of antiviral genes as cells were first treated with IFN- $\lambda 1$ and then infected. It is noteworthy that DENV-2 infection induced ISG transcripts but that these did not reach the levels observed when cells were stimulated with IFN- $\lambda 1$. However, when cells were pre-treated with IFN- $\lambda 1$ and then infected, ISG transcript levels were significantly higher and were maintained longer than in the DENV-2-infected group. SOCS1 and SOCS3 were induced after ISGs reached their highest peaks, which may denote the negative action exerted on the IFN-activated JAK/STAT pathway. However, the analyzed ISGs in the presence of IFN- $\lambda 1$ stimulation remained at low levels but were sufficient to reach a second expression peak capable of inhibiting viral replication at late stages, which explains the decrease in viral titers observed between 18 and $48 \mathrm{~h}$ (Fig. 6).

The antiviral genes MX1 and OAS1 showed an early activation at $6 \mathrm{~h}$ and peaked at 18 and $48 \mathrm{~h}$, respectively, in the IFN- $\lambda 1 / \mathrm{DENV}-2$ group. OAS1 mRNA was higher when cells were pre-treated with IFN- $\lambda 1$ and subsequently infected compared to cells that were stimulated only with IFN- $\lambda 1$. This outcome was likely due to increased activation of the gene in the presence of infection plus gene activation mediated by interferon.
OAS1 has antiviral activity against DENV-2 infection [33]. The OAS/RNase L antiviral system is induced via IFN and plays a critical role in innate immunity, controlling the production of viral particles. RNase L possesses antiviral action, cleaving the viral RNA, inducing apoptosis in infected cells, and increasing the production of IFN- $\beta$ through MDA5/RIG-I/IPS-I [34].

Higher activation of the MX1 gene occurs through stimulation of IFN- $\lambda 1$ because it is a gene-specific interferon response, which indicates the proper functioning of the pathway in the cell line. In the case of the IFN$\lambda 1 / \mathrm{DENV}-2$ experiments, increased expression was most likely caused by pre-treatment with IFN- $\lambda 1$ because the DENV-2-infected group showed no transcript increase for this gene. It is significant that although the transcript levels were as high as when cells were stimulated only with IFN- $\lambda 1$, the observed levels may be sufficient to inhibit viral replication even with the activation of the SOCS genes, whose levels appear not be sufficient to completely inhibit the transcription of MX1 at later times.

Transcription levels of ISGs in different groups showed a clear relationship between treatment with IFN $-\lambda$ and its role in inhibition of DENV-2 replication. It is possible to observe a process of evasion of the immune response, most likely mediated by viral infection, showing a decrease in the transcription of evaluated ISGs in DENV-2 infected cells compared with cells stimulated with IFN- $\lambda$ and an increase in SOCS1 and SOCS3 genes.

However, the IFN- $\lambda 1$ gene was activated initially and then in the last times evaluated (6 and $48 \mathrm{~h}$ postinfection), suggesting its escape from the suppressor activity of SOCS proteins. When cells were stimulated with IFN- $\lambda 1$ and then infected, there was a slight and steady increase in the evaluated ISGs, which peaked at 12 or 18 and $48 \mathrm{~h}$ post-infection, suggesting that activity of the pathway is only partially affected by viral evasion. These findings suggest that IFN-I and IFN-III are not always concomitantly expressed and support the idea that there are differences in the regulatory mechanisms of their expression and in the group of genes that can be individually or jointly activated [35].

It is noteworthy that the highest peaks of the evaluated ISGs (12 and $18 \mathrm{~h}$ ) corresponded to the time when the viral titer was reduced in culture supernatants; thus, greater inhibition of viral titer was achieved when ISGs reached their peaks $(48 \mathrm{~h})$. These findings suggest that inhibition of viral titer was caused by IFN- $\lambda$ treatment and by the activation of genes in response to interferon, whose antiviral action in the cells inhibited the replication of DENV-2.

IFN- $\lambda$ production increases after treatment with IFN$\alpha$ prior to viral infection [36, 37]. Our results suggest that IFN-III enhances the expression of IFN-I as pre- 
treatment with IFN- $\lambda 1$ increased IFN- $\beta$ expression during infection with dengue virus. This leads us to propose that the crosstalk between interferon type I and III pathways may exist in some cells, like mononuclear or plasmacytoid dendritic cells, to produce and respond to both types of interferon [38, 39]. However, these are not necessarily redundant systems as shown in our experiments, wherein the expression of IFN- $\lambda 1$ exists despite the evasion of the immune response mounted by DENV- 2 .

In the absence of antiviral drugs against DENV, this paper suggests that interferon lambda could be a valuable candidate to explore in clinical studies. In addition, the immunomodulatory properties reported for IFN- $\lambda$ [13] can contribute to the regulation of the inflammatory process characteristic of dengue. Studies with IFN- $\alpha$ in Japanese encephalitis models have shown decreased inflammation [40], but treatment with IFN- $\alpha$ has side effects associated with the ubiquitous expression of its receptor [19, 20, 41]. In contrast, the narrow expression of type III interferon receptor could considerably diminish side effects of IFN- $\lambda$ clinical use.

\section{Conclusions}

This is the first report of increased levels of IFN-III in dengue fever patients in vivo and of the antiviral effect of IFN-III on DENV-2 infection in vitro; however, aspects of the activation of this pathway and its crosstalk with IFN-I remain unanswered.

The epithelial cell line C33-A is a useful model for in vitro mechanistic studies on DENV replication and its interaction with the innate response led by IFN-III. In infection studies, IFN- $\lambda 1$ and IFN- $\lambda 2$ inhibited DENV- 2 replication in a dose-dependent manner. In Vero cells, which do not produce IFN- $\alpha$, viral replication inhibition by exogenous IFN- $\lambda 1$ was also observed, although at higher concentrations, suggesting that IFN- $\lambda 1$ itself can inhibit the infection, however the potential to decrease the viral load increases with the presence of IFN- $\alpha$. DENV-2 infection induces IFN- $\lambda 1$ expression but not of IFN- $\beta$. Exogenous IFN- $\lambda 1$ induced the transcription of several ISGs whose expression peaks corresponded to the time when viral titer was reduced in culture supernatants (12, 18, and $48 \mathrm{~h}$ post-infection). The present work opens the possibility for the study of other interactions and mechanisms of DENV infection with IFN-III in this cell model and presents an opportunity to consider this type of IFN as a feasible candidate for the inhibition of infection in dengue patients.

\section{Methods \\ Cells}

Human cervical carcinoma C33-A (ATCC: CRM-HTB-31), African green monkey kidney Vero (ATCC: CCL81, kindly donated by Dr. Judith González, Universidad Autónoma del Estado de Morelos, Mexico) and baby hamster kidney BHK-21 (C-13) (ATCC: CCL-10) cell lines were maintained in Dulbecco's Modified Eagle's Medium (DMEM) supplemented with $10 \%$ fetal calf serum, $100 \mathrm{U} / \mathrm{mL}$ penicillin and $100 \mu \mathrm{g} / \mathrm{mL}$ streptomycin at $37{ }^{\circ} \mathrm{C}$ with $5 \% \mathrm{CO}_{2}$. Aedes albopictus C6/36 cells (kindly donated by Dr. Celso Ramos, Instituto Nacional de Salud Pública, Cuernavaca, Mexico) were maintained in Minimum Essential Medium (MEM) supplemented with $10 \%$ fetal calf serum, $100 \mathrm{U} /$ $\mathrm{mL}$ penicillin and $100 \mu \mathrm{g} / \mathrm{mL}$ at $27^{\circ} \mathrm{C}$.

\section{Virus}

Dengue virus serotype 2 (Thailand/16681/1984) (DENV-2) used in this study was kindly provided by Dr. Alvaro Aguilar-Setien. DENV-2 was replicated in C6/36 cells and titrated by plaque assay in BHK-21 cells [42].

\section{Clinical samples}

Serum samples from dengue patients collected from June to September 2013, were analyzed to determine the IFN- $\lambda$. All serum samples were maintained at $-70{ }^{\circ} \mathrm{C}$, thawed onto ice and immediately subjected to ELISA. Patients were recruited in the Regional Hospital at Mepetec, Puebla, Mexico. All patients had signs of dengue fever and DENV infection was confirmed by IgM antibodies and viral NS1 antigen detection. The samples from included patients were obtained between days 3 and 5 after fever onset. Sampling and patient information management were performed following ethical regulations approved by Local Research and Health Ethics Committee \#2101 of Mexican Institute for Social Security, IMSS (Protocol: R-2011-2103-24) and in accordance with the Declaration of Helsinki. Written informed consent was obtained from each participant. Controls were serum samples of healthy blood donors submitted to conventional studies at the hospital blood bank and were used to compare IFN- $\lambda$ levels.

\section{Infection assays}

C33-A or Vero cells were seeded onto 12- or 24-well plates and infected with different virus doses [quantified by multiplicity of infection (MOI)]. Viral inocula were incubated for $1 \mathrm{~h}$ and then discarded. Cells were washed twice to eliminate non-adsorbed virus. Fresh medium (SFB $2.5 \%$ ) was added to the cells and then incubated for hours or days depending on the specific assay.

\section{Cell stimulation}

Cells were treated prior to infection for $6 \mathrm{~h}$ with 100-500 $\mathrm{UI} / \mathrm{ml}$ of IFN- $\alpha$ (Probiomed, Mexico city, Mexico.), $10-50 \mathrm{ng} / \mathrm{ml}$ of IFN- $\lambda 1$ (PeproTech, Rocky Hill, NJ, USA) or $10-50 \mathrm{ng} / \mathrm{ml}$ IFN- $\lambda 2$ (PeproTech). A poly(I:C) (InvivoGen, San Diego, CA, USA) control treatment 
was performed on cells using DMEM without SFB and $100 \mu \mathrm{g} / \mathrm{ml}$ of poly(I:C).

\section{Western blot}

Infected cells or mock-infected cells, previously treated or mock-treated with IFNs for $6 \mathrm{~h}$, were analyzed in order to determine the induction of IFN- $\lambda 1$ and IFN $-\lambda 2$. Total extracts of cells were obtained $48 \mathrm{~h}$ post-infection and subjected to SDS-PAGE using a $15 \%$ resolving gel. Proteins in gel were transferred to PVDF membranes and detected by anti-IFN- $\lambda 1$ (Santa Cruz Biotechnology, Santa Cruz, CA, USA, sc-67642), anti-IFN- $\lambda 2$ (Abcam, Cambridge, MA, USA, ab109820) and anti- $\beta$-actin specific antibodies (Abcam, mAbcam8226). Primary antibodies were revealed with a goat anti-rabbit IgG-HRP (Santa Cruz Biotechnology, sc-2004), rabbit anti-goat IgG-HRP (Abcam, ab6741) or goat anti-mouse IgG-HRP (ab97023) and the Immobilon Western chemiluminescence system (Millipore-Merck, Darmstadt, Germany).

\section{Fluorescence microscopy}

C33-A cells were seeded onto glass chamber slides (Lab-Tek, Nalgene Nunc, Rochester, NY, USA) and infected as mentioned above. Infected or non-infected controls were washed with phosphate-buffered saline (PBS) and fixed in ethanol/acetone $50 \% \mathrm{v} / \mathrm{v}$ for $10 \mathrm{~min}$ at room temperature. Cells were permeabilized with $0.2 \%$ Triton-X100 for $2 \mathrm{~min}$ in order to detect the viral pr-M protein inside infected cells and incubated in blocking solution (PBS with $10 \%$ FBS and $0.2 \%$ Tween
20). Cells were labelled with anti-dengue virus pr-M antibody (Abcam, ab41473) or anti-IL28R (Santa Cruz Biotechnology, sc-66541), washed and incubated with rabbit anti-mouse IgG-Texas red (Abcam, ab6726) or bovine anti-goat IgG-CFL-647 (Santa Cruz Biotechnology, sc-362284) for $1 \mathrm{~h}$ at room temperature. SYBR-14 dye (Molecular Probes, Eugene, OR, USA) was used to stain the nuclei. The stained cells were visualized by laser confocal microscopy system E600-C1 using the image analysis software EZ-C1 (Nikon).

\section{Real time PCR}

Total RNA of DENV-2 infected and/or stimulated cells was extracted using Trizol (Invitrogen, Carlsbad, CA, USA) according to the manufacturer's instructions, treated with DNase I (Thermo Scientific, Waltham, MA, USA) and quantified at 260/280 nm. Reverse transcription was performed using RevertAid H Minus Reverse Transcriptase kit (Thermo Scientific) and random hexamers. The reaction program was $25{ }^{\circ} \mathrm{C}$ for $10 \mathrm{~min}$, $42{ }^{\circ} \mathrm{C}$ for $60 \mathrm{~min}$ and $70{ }^{\circ} \mathrm{C}$ for $10 \mathrm{~min}$. The obtained cDNA was used to amplify the IFN- $\beta$, OAS1 and MX1 genes using the Taqman Universal PCR Master Mix, no AmpErase UNG kit (Applied Biosystems, Foster City, CA, USA). IFN- $\lambda 1$, SOCS1 and SOCS3 genes were amplified using Maxima SYBR Green/ROX qPCR Master Mix (Thermo Scientific). The reaction mixture contained $5 \mu \mathrm{l} 2 \mathrm{X}$ Master Mix, $200 \mathrm{nM}$ of each sense and antisense primer, $200 \mathrm{nM}$ of Taqman probe and 35-50 ng RNA in a final volume of $10 \mu \mathrm{l}$. Forty PCR cycles were performed at

Table 1 Primers used in the present study

\begin{tabular}{|c|c|c|c|c|}
\hline $\begin{array}{l}\text { Gene name and accession } \\
\text { number in GenBank }\end{array}$ & Sequence $\left(5^{\prime}-3^{\prime}\right)$ & UPL sequence $(U P L \#)^{a}$ & $\begin{array}{l}\text { Amplicon } \\
\text { bp }\end{array}$ & Alignment $^{b}$ \\
\hline MX1 & TCCAGCCACCATTCCAAG & \multirow[t]{2}{*}{ TTCTCCTG (2) } & \multirow[t]{2}{*}{60} & $868-885$ \\
\hline NM_001144925.2 & CAACAAGTTAAATGGTATCACAGAGC & & & $927-902$ \\
\hline OAS1 & GGTGGAGTTCGATGTGCTG & \multirow[t]{2}{*}{ CCAGGGCA (37) } & \multirow[t]{2}{*}{64} & $538-556$ \\
\hline XM_006719434.1 & AGGTTTATAGCCGCCAGTCA & & & $601-582$ \\
\hline IFN- $\beta$ & CTTGGTATTTCAGACAAGATTCA & \multirow[t]{2}{*}{ CTGGCTGG (20) } & \multirow[t]{2}{*}{69} & $336-360$ \\
\hline NM_002176.2 & GCCAGGAGGTTCTCAAGAAT & & & 404-389 \\
\hline $\mid F N-\lambda 1$ & TCCTAGACCAGCCCCTTCA & \multirow[t]{2}{*}{ c } & \multirow[t]{2}{*}{73} & $435-453$ \\
\hline NM_172140.1 & GTGGGCTGAGGCTGGATA & & & $507-490$ \\
\hline $\mathrm{IFN}-\lambda 2$ & CCTGGTGGACGTCTTGGA & \multirow[t]{2}{*}{ c } & \multirow[t]{2}{*}{84} & $406-423$ \\
\hline NM_172138.1 & GTGGGCTGAGGCTGGATA & & & $489-472$ \\
\hline IFN- $\lambda 3$ & AGGGCCAAAGATGCCTTAG & \multirow[t]{2}{*}{ c } & \multirow[t]{2}{*}{123} & $167-185$ \\
\hline NM_172139.2 & CAGCTCAGCCTCCAAAGC & & & $298-281$ \\
\hline HPRT1 & - & - & 127 & - \\
\hline NM_000194.2 $2^{d}$ & & & & \\
\hline
\end{tabular}

${ }^{a}$ UPL: Universal Probe Library, Roche Life Science. Number of the probe is in parentheses

${ }^{\mathrm{b}}$ Position of primers in the corresponding gene sequences

'SybrGreen dye was used

${ }^{\mathrm{d}}$ Specific gene positions and sequences of Applied Biosystems primers and probes are not disclosed 
$50{ }^{\circ} \mathrm{C}$ for $2 \mathrm{~min}, 94{ }^{\circ} \mathrm{C}$ for $10 \mathrm{~min}, 95^{\circ} \mathrm{C}$ for $15 \mathrm{~s}, 60{ }^{\circ} \mathrm{C}$ for $30 \mathrm{~s}$ and $72{ }^{\circ} \mathrm{C}$ for $30 \mathrm{~s}$ in a StepOne Real-Time PCR System (Applied Biosystems). Specific primers for IFN- $\lambda 1$, IFN- $\beta$, OAS1 and MX1 genes were designed using ProbeFinder Assay Design Software (Roche, Basel, Switzerland, www.universalprobelibrary.com) in order to use the Taqman probes of Universal ProbeLibrary Set, Human (Roche). In all cases, HPRT1 (Hypoxanthine Guanine Phosphoribosyl Transferase) gene was used as an internal control to determine the relative expression of each gene. All primers were purchased from Integrated DNA Technologies (Coralville, IA, USA). Obtained Ct values were analyzed by the $2-\Delta \Delta \mathrm{Ct}$ method, and the expression levels were reported as proportions with respect to controls. Sequences of primers and probes are shown in Table 1.

\section{ELISA}

Levels of IFN- $\lambda$ in the serum of patients were measured using enzyme-linked immunosorbent assay (ELISA) kit specific for IFN- $\lambda 1$ and $\lambda 3$ (DY1598B, R\&D systems, Inc. Minneapolis, USA). The ELISA was performed according to the manufacturer's instructions.

\section{Statistical analysis}

Quantitative analyses were performed in triplicate in at least two different assays. Two-way ANOVA and Bonferroni test were performed using GraphPad Prism 5 (GraphPad Software, La Jolla, CA, USA). Differences with $p<0.05$ were considered statistically significant.

\section{Competing interests}

The authors declare that they have no competing interests.

\section{Authors' contributions \\ HKPO, NHRM, WR and GSL participated in the study design; HKPO performed the infection and qPCR experiments. JRL and JCFA performed the confocal microscopy analysis; LFM and HKPO handled the samples and clinical data of patients and performed the ELISA assays; HKPO, WR and NHRM analyzed data, performed the statistical analyses and reviewed the manuscript. NHRM and GSL coordinated the study and the writing of the manuscript. All authors read and approved the final manuscript.}

\section{Acknowledgements}

This work was supported by Instituto Mexicano del Seguro Social (IMSS/FIS/ PROT/G11/975), Funds for Scientific Infrastructure from the IMSS (CTFIS/ 10RD/12/2011) and Redes Temáticas-SEP 2012 México. HKPO obtained scholarships from CONACYT (209395) and IMSS (98222353). We thank Dr. Paulina Cortés-Hernández for critical review and suggestions to this article.

\footnotetext{
Author details

'Laboratorio de Biología Molecular y Virología, Centro de Investigación Biomédica de Oriente, Instituto Mexicano del Seguro Social, Metepec, Puebla, México. ${ }^{2}$ Laboratorio de Inmunología, Centro de Investigación Biomédica de Oriente, Instituto Mexicano del Seguro Social, Puebla, México. ${ }^{3}$ Posgrado en Ciencias Químicas, Benemérita Universidad Autónoma de Puebla, Puebla, México. ${ }^{4}$ Laboratorio de Bioquímica, Centro de Química, Instituto de Ciencias, Benemérita Universidad Autónoma de Puebla, Puebla, México.
}

Received: 4 March 2015 Accepted: 16 September 2015

Published online: 28 September 2015

\section{References}

1. Bhatt S, Gething PW, Brady OJ, Messina JP, Farlow AW, Moyes CL, et al. The global distribution and burden of dengue. Nature. 2013;496(7446):504-7. doi:10.1038/nature12060.

2. Guzman MG, Halstead SB, Artsob H, Buchy P, Farrar J, Gubler DJ, et al. Dengue: a continuing global threat. Nat Rev Microbiol. 2010;8(12 Suppl):S7-16. doi:10.1038/nrmicro2460.

3. Perera R, Kuhn RJ. Structural proteomics of dengue virus. Curr Opin Microbiol. 2008;11(4):369-77. doi:10.1016/j.mib.2008.06.004.

4. WHO. Dengue haemorrhagic fever: diagnosis, treatment, prevention and control. 2nd ed. Geneva, Switzerland: WHO; 1997.

5. Hales S, de Wet N, Maindonald J, Woodward A. Potential effect of population and climate changes on global distribution of dengue fever: an empirical model. Lancet. 2002;360(9336):830-4. doi:10.1016/S0140-6736(02)09964-6.

6. Randall RE, Goodbourn S. Interferons and viruses: an interplay between induction, signalling, antiviral responses and virus countermeasures. J Gen Vvirol. 2008:89(Pt 1):1-47. doi:10.1099/vir.0.83391-0.

7. Rodriguez-Madoz JR, Belicha-Villanueva A, Bernal-Rubio D, Ashour J, Ayllon J, Fernandez-Sesma A. Inhibition of the type I interferon response in human dendritic cells by dengue virus infection requires a catalytically active NS2B3 complex. J Virol. 2010;84(19):9760-74. doi:10.1128/JVI.01051-10.

8. de Weerd NA, Nguyen T. The interferons and their receptors-distribution and regulation. Immunol Cell Biol. 2012;90(5):483-91. doi:10.1038/icb.2012.9.

9. Stetson DB, Medzhitov R. Antiviral defense: interferons and beyond. J Exp Med. 2006;203(8):1837-41. doi:10.1084/jem.20061377.

10. Kotenko SV, Gallagher G, Baurin W, Lewis-Antes A, Shen M, Shah NK, et al. IFN-lambdas mediate antiviral protection through a distinct class II cytokine receptor complex. Nat Immunol. 2003;4(1):69-77. doi:10.1038/ni875ni875.

11. Sheppard P, Kindsvogel W, Xu W, Henderson K, Schlutsmeyer S, Whitmore TE, et al. IL-28, IL-29 and their class II cytokine receptor IL-28R. Nat Immunol. 2003;4(1):63-8. doi:10.1038/ni873ni873.

12. Prokunina-Olsson L, Muchmore B, Tang W, Pfeiffer RM, Park H, Dickensheets $\mathrm{H}$, et al. A variant upstream of IFNL3 (IL28B) creating a new interferon gene IFNL4 is associated with impaired clearance of hepatitis C virus. Nat Genet. 2013;45(2):164-71. doi:10.1038/ng.2521.

13. Li M, Liu X, Zhou Y, Su SB. Interferon-lambdas: the modulators of antivirus, antitumor, and immune responses. J Leukoc Biol. 2009;86(1):23-32. doi:10.1189/jlb.1208761.

14. Pagliaccetti NE, Robek MD. Interferon-lambda in the immune response to hepatitis B virus and hepatitis C virus. J Interferon Cytokine Res. 2010;30(8):585-90. doi:10.1089/jir.2010.0060.

15. Hou W, Wang $X$, Ye L, Zhou L, Yang ZQ, Riedel E, et al. Lambda interferon inhibits human immunodeficiency virus type 1 infection of macrophages. J Virol. 2009;83(8):3834-42. doi:10.1128/JVI.01773-08.

16. Sommereyns C, Paul S, Staeheli P, Michiels T. IFN-lambda (IFN-lambda) is expressed in a tissue-dependent fashion and primarily acts on epithelial cells in vivo. PLoS Pathog. 2008;4(3), e1000017. doi:10.1371/journal.ppat.1000017.

17. Witte K, Gruetz G, Volk HD, Looman AC, Asadullah K, Sterry W, et al. Despite IFN-lambda receptor expression, blood immune cells, but not keratinocytes or melanocytes, have an impaired response to type III interferons: implications for therapeutic applications of these cytokines. Genes Immun. 2009;10(8):702-14. doi:10.1038/gene.2009.72.

18. Limonta Vidal M, Ramírez Albajes V, López Saura P, Aguilera A, Pentón E, Barcelona S, et al. Use of leukocyte interferon during an epidemic outbreak of haemorragic dengue (Type II) in Cuba. Interferon Biotecnol. 1984;1(3):15-22.

19. Okanoue T, Sakamoto S, Itoh Y, Minami M, Yasui K, Sakamoto M, et al. Side effects of high-dose interferon therapy for chronic hepatitis $C$. J Hepatol. 1996;25(3):283-91.

20. Muir AJ, Shiffman ML, Zaman A, Yoffe B, de la Torre A, Flamm S, et al. Phase $1 \mathrm{~b}$ study of pegylated interferon lambda 1 with or without ribavirin in patients with chronic genotype 1 hepatitis $C$ virus infection. Hepatology. 2010;52(3):822-32. doi:10.1002/hep.23743.

21. Scagnolari C, Vicenzi E, Bellomi F, Stillitano MG, Pinna D, Poli G, et al. Increased sensitivity of SARS-coronavirus to a combination of human type I and type II interferons. Antivir Ther. 2004;9(6):1003-11.

22. Stoltz M, Klingstrom J. Alpha/beta interferon (IFN-alpha/beta)-independent induction of IFN-lambda1 (interleukin-29) in response to Hantaan virus infection. J Virol. 2010;84(18):9140-8. doi:10.1128/JVI.00717-10.

23. Ank N, Iversen MB, Bartholdy C, Staeheli P, Hartmann R, Jensen UB, et al. An important role for type III interferon (IFN-lambda/IL-28) in TLR-induced antiviral activity. J Immunol. 2008;180(4):2474-85. 
24. Mordstein M, Kochs G, Dumoutier L, Renauld JC, Paludan SR, Klucher K, et al. Interferon-lambda contributes to innate immunity of mice against influenza A virus but not against hepatotropic viruses. PLoS Pathog. 2008:4(9), e1000151. doi:10.1371/journal.ppat.1000151.

25. De La Cruz Hernandez SI, Puerta-Guardo H, Flores-Aguilar H, GonzalezMateos S, Lopez-Martinez I, Ortiz-Navarrete V, et al. A strong interferon response correlates with a milder dengue clinical condition. J Clin Virol. 2014;60(3):196-9. doi:10.1016/j.jcv.2014.04.002.

26. Ank N, West H, Bartholdy C, Eriksson K, Thomsen AR, Paludan SR. Lambda interferon (IFN-lambda), a type III IFN, is induced by viruses and IFNs and displays potent antiviral activity against select virus infections in vivo. J Virol. 2006:80(9):4501-9. doi:10.1128/JVI.80.9.4501-4509.2006.

27. Pagliaccetti NE, Chu EN, Bolen CR, Kleinstein SH, Robek MD. Lambda and alpha interferons inhibit hepatitis B virus replication through a common molecular mechanism but with different in vivo activities. Virology. 2010;401 (2):197-206. doi:10.1016/j.virol.2010.02.022.

28. Robek MD, Boyd BS, Chisari FV. Lambda interferon inhibits hepatitis B and C virus replication. J Virol. 2005;79(6):3851-4. doi:10.1128/ JVI.79.6.3851-3854.2005.

29. Doyle SE, Schreckhise H, Khuu-Duong K, Henderson K, Rosler R, Storey H, et al. Interleukin-29 uses a type 1 interferon-like program to promote antiviral responses in human hepatocytes. Hepatology. 2006;44(4):896-906. doi:10.1002/ hep.21312.

30. Ma D, Jiang D, Qing M, Weidner JM, Qu X, Guo H, et al. Antiviral effect of interferon lambda against West Nile virus. Antiviral Res. 2009;83(1):53-60. doi:10.1016/j.antiviral.2009.03.006.

31. Desmyter J, Melnick JL, Rawls WE. Defectiveness of interferon production and of rubella virus interference in a line of African green monkey kidney cells (Vero). J Virol. 1968;2(10):955-61.

32. Diaz MO, Ziemin S, Le Beau MM, Pitha P, Smith SD, Chilcote RR, et al. Homozygous deletion of the alpha- and beta 1-interferon genes in human leukemia and derived cell lines. Proc Natl Acad Sci U S A. 1988;85(14):5259-63.

33. Lin RJ, Yu HP, Chang BL, Tang WC, Liao CL, Lin YL. Distinct antiviral roles for human 2',5'-oligoadenylate synthetase family members against dengue virus infection. J Immunol. 2009;183(12):8035-43. doi:10.4049/jimmunol.0902728.

34. Li XL, Blackford JA, Hassel BA. RNase $L$ mediates the antiviral effect of interferon through a selective reduction in viral RNA during encephalomyocarditis virus infection. J Virol. 1998;72(4):2752-9.

35. Iversen MB, Paludan SR. Mechanisms of type III interferon expression. J Interferon Cytokine Res. 2010;30(8):573-8. doi:10.1089/jir.2010.0063.

36. Osterlund P, Veckman V, Siren J, Klucher KM, Hiscott J, Matikainen S, et al. Gene expression and antiviral activity of alpha/beta interferons and interleukin-29 in virus-infected human myeloid dendritic cells. J Virol. 2005;79(15):9608-17. doi:10.1128/JVI.79.15.9608-9617.2005.

37. Siren J, Pirhonen J, Julkunen I, Matikainen S. IFN-alpha regulates TLRdependent gene expression of IFN-alpha, IFN-beta, IL-28, and IL-29. J Immunol. 2005;174(4):1932-7.

38. Melchjorsen J, Siren J, Julkunen I, Paludan SR, Matikainen S. Induction of cytokine expression by herpes simplex virus in human monocyte-derived macrophages and dendritic cells is dependent on virus replication and is counteracted by ICP27 targeting NF-kappaB and IRF-3. J Gen Virol. 2006:87(Pt 5):1099-108. doi:10.1099/vir.0.81541-0.

39. Zhang S, Kodys K, Li K, Szabo G. Human type 2 myeloid dendritic cells produce interferon-lambda and amplify interferon-alpha in response to hepatitis $C$ virus infection. Gastroenterology. 2013;144(2):414-25. doi:10.1053/j.gastro.2012. 10.034. e7

40. Harinasuta C, Nimmanitya S, Titsyakorn U. The effect of interferon-alpha A on two cases of Japanese encephalitis in Thailand. Southeast Asian J Trop Med Public Health. 1985:16(2):332-6.

41. Sleijfer S, Bannink M, Van Gool AR, Kruit WH, Stoter G. Side effects of interferon-alpha therapy. Pharm World Sci. 2005;27(6):423-31. doi:10.1007/s11096-005-1319-7.

42. Diamond MS, Edgil D, Roberts TG, Lu B, Harris E. Infection of human cells by dengue virus is modulated by different cell types and viral strains. J Virol. 2000;74(17):7814-23.

\section{Submit your next manuscript to BioMed Central and take full advantage of:}

- Convenient online submission

- Thorough peer review

- No space constraints or color figure charges

- Immediate publication on acceptance

- Inclusion in PubMed, CAS, Scopus and Google Scholar

- Research which is freely available for redistribution

Submit your manuscript at www.biomedcentral.com/submit 